\title{
Vitamin D deficiency in Korean children: prevalence, risk factors, and the relationship with parathyroid hormone levels
}

In Hyuk Chung, MD', Hae Jung Kim, $M D^{2}$, Sochung Chung, MD, PhD ${ }^{3}$, Eun-Gyong Yoo, MD, $\mathrm{PhD}^{2}$

${ }^{1}$ Department of Pediatrics, National Health Insurance Corporation Ilsan Hospital, Goyang, ${ }^{2}$ Department of Pediatrics, CHA Bundang Medical Center, CHA University College of Medicine, Seongnam, ${ }^{3}$ Department of Pediatrics, Konkuk University Medical Center, Konkuk University School of Medicine, Seoul, Korea
Purpose: : This study was performed to investigate the relationship between serum vitamin $D$ and parathyroid hormone (PTH) levels as well as to describe the prevalence and the risk factors of vitamin D deficiency (VDD) in Korean children. Methods: Participants were 1,212 children aged 4 to 15 years, who visited Bundang CHA Medical Center (located at 37० N) between March 2012 and February 2013. Overweight was defined as body mass index $\geq 85$ th percentile. Participants were divided into 4 age groups and 2 seasonal groups. VDD was defined by serum 25 -hydroxyvitamin D (25OHD) $<20 \mathrm{ng} / \mathrm{mL}$.

Results: The level of $25 \mathrm{OHD}$ was significantly lower in overweight group than in normal weight group $(17.1 \pm 5.1 \mathrm{ng} / \mathrm{mL}$ vs. $19.1 \pm 6.1 \mathrm{ng} / \mathrm{mL}, P<0.001)$. Winter-spring season (odds ratio [OR], 4.46; 95\% confidence interval [Cl], 3.45-5.77), older age group (OR, 1.60; 95\% Cl, 1.36-1.88), and overweight (OR, 2.21; 95\% Cl, 1.62-3.01) were independently related with VDD. The PTH levels were significantly higher in VDD group compared to vitamin $D$ insufficiency and sufficiency group $(P<0.001)$. In normal weight children, 25OHD $(\beta=-0.007, P<0.001)$ and ionized calcium $(\beta=-0.594$, $P=0.007$ ) were independently related with PTH, however, these associations were not significant in overweight children.

Conclusion: VDD is very common in Korean children and its prevalence increases in winter-spring season, in overweight children and in older age groups. Further investigation on the vitamin D and PTH metabolism according to adiposity is required.

Keywords: Vitamin D, Parathyroid hormone, Body mass index, Calcium

\section{Introduction}

Vitamin D is essential for maintaining skeletal health and optimal growth in children. It also regulates numerous cellular functions, and studies revealed associations between vitamin D deficiency (VDD) and the risk of metabolic syndrome, diabetes, autoimmune diseases, and some types of cancer $^{1-4)}$.

VDD is very common nowadays in children as well as in adults, probably due to decreased exposure to sunlight $t^{5}$. According to the Korean National Health and Nutrition Examination Survey 2008, the prevalence of VDD was $47 \%$ in teenage boys and $65 \%$ in teenage girls . However, data on the prevalence and risk factors of VDD in younger children are limited in Korea.

The prevalence of VDD increases in obese individuals because adipose tissue sequesters vitamin D3, and obese individuals may require at least 2 to 3 times more vitamin D to achieve optimal serum 25-hydroxyvitamin D (25OHD) level ${ }^{7,8)}$. However, there is no consensus if it is 
relevant to maintain the $25 \mathrm{OHD}$ levels within the same target range in overweight and normal weight children.

This study was performed to investigate (1) the prevalence and risk factors of VDD in Korean children and (2) the relationship between $25 \mathrm{OHD}$ and parathyroid hormone $(\mathrm{PTH})$ levels in normal weight and overweight children.

\section{Materials and methods}

\section{Participants}

Participants were 1,212 children aged 4 to 15 years who visited Bundang CHA Medical Center (located at latitude of $37^{\circ} \mathrm{N}$ ) for checkup of their health and growth status between March 2012 and February 2013. Exclusion criteria were (1) children with body mass index $(\mathrm{BMI})<3$ rd percentile, (2) those with abnormal laboratory results (abnormal liver, kidney, or thyroid function test, or hemoglobin level $<11 \mathrm{~g} / \mathrm{dL}$ ), and (3) those who were treated with gonadotropin-releasing hormone analogue, growth hormone, or other chronic diseases. Normal weight was defined by BMI 3rd to 84th percentile, and overweight was defined by $\mathrm{BMI} \geq 85$ th percentile for age and sex based on Korean standard growth curve. Participants were divided into four age groups ( $4-6$ years, $n=174 ; 7-9$ years, $n=570 ; 10-12$ years, $n=368$ years, and $13-15$ years, $\mathrm{n}=100$ ) and two seasonal groups (winter-spring [December to May] vs. summer-fall [June to November]). This study was approved by the Institutional Review Board of Bundang CHA Medical Center.

\section{Laboratory measurement}

Serum 25OHD was measured by chemiluminescence immunoassay (LIAISON system, DiaSorin, Italy). PTH was measured by electrochemiluminescence immunoassay (Roche Diagnostic, Indianapolis, IN, USA). Serum calcium, phosphorus, and alkaline phosphatase levels were measured by spectrophotometric method (HITACHI automatic analyzer, Tokyo, Japan). Ionized calcium was measured in 282 children (216 normal weight and 66 overweight children) by spectrophotometric method (HITACHI automatic analyzer).

Children were divided into 3 groups according to their vitamin D status; deficiency (25OHD, $<20 \mathrm{ng} / \mathrm{mL}$ ), insufficiency (25OHD, 20-30 ng/mL), and sufficiency (25OHD, $\geq 30 \mathrm{ng} /$ $\mathrm{mL})^{8)}$.

\section{Statistical analysis}

Statistical analysis was performed by IBM SPSS ver. 20.0 (IBM Co., Armonk, NY, USA). Mean levels for collected variables were compared by Student $t$-test. Chi-square test was used to compare the prevalence of VDD between groups. A logistic regression model was applied to investigate factors independently related to VDD. Analysis of variance with Bonferroni post hoc test was used to compare the PTH levels according to vitamin D status. Pearson correlation was used to evaluate the association between PTH, 25OHD, and ionized calcium. Multiple regression analysis was performed to verify factors related to PTH levels. Because the PTH data was not normally distributed, it was natural log transformed before using in the correlation or regression analysis. A $P$-value $<0.05$ was considered significant.

\section{Results}

\section{Demographic and laboratory characteristics of participants}

Baseline characteristics of normal weight ( $n=967$ ) overweight $(\mathrm{n}=245)$ children are shown in Table $1.25 \mathrm{OHD}$ was significantly lower in overweight group than in normal weight group $(17.1 \pm 5.1 \mathrm{ng} / \mathrm{mL}$ vs. $19.1 \pm 6.1 \mathrm{ng} / \mathrm{mL}, P<0.001)$ (Table 1$)$.

\section{The prevalence of VDD according to season, age, and adiposity}

Among the total participants, 58.6\% was vitamin D deficient, $38.5 \%$ was vitamin D insufficient, and only $2.9 \%$ was vitamin D sufficient. Gender difference in vitamin D status was not observed. When participants were stratified by age group, the proportion of VDD increased with advancing age group (4-6 years, $44.3 \%$; 7-9 years, $56.8 \%$; $10-12$ years, $63.0 \%$; and $13-15$ years, $77.0 \%$; $P$ for trend $<0.001)$. The prevalence of VDD was $43.1 \%$ in the summer-fall season, but it increased to $75.1 \%$ in winter-spring season $(P<0.001)$.

Table 1. Clinical and laboratory characteristics of participants

\begin{tabular}{lccc}
\hline Characteristic & $\begin{array}{c}\text { Normal weight } \\
(\mathrm{n}=967)\end{array}$ & $\begin{array}{c}\text { Overweight } \\
(\mathrm{n}=245)\end{array}$ & P-value \\
\hline Male sex & $270(27.9)$ & $68(27.8)$ & $\mathrm{NS}$ \\
Season (summer-fall) & $508(52.5)$ & $118(48.2)$ & $\mathrm{NS}$ \\
Vitamin D status & & & \\
Deficiency & $535(55.3)$ & $175(71.4)$ & $<0.001$ \\
Insufficiency & $401(41.5)$ & $66(26.9)$ & $<0.001$ \\
Sufficiency & $31(3.2)$ & $4(1.6)$ & $\mathrm{NS}$ \\
Age (yr) & $9.2 \pm 2.3$ & $8.7 \pm 2.4$ & $<0.001$ \\
BMI (kg/m $\left.{ }^{2}\right)$ & $17.0 \pm 2.1$ & $22.2 \pm 2.6$ & $<0.001$ \\
BMI z score & $-0.3 \pm 0.7$ & $1.6 \pm 0.5$ & $<0.001$ \\
Height z score & $-0.7 \pm 1.2$ & $0.3 \pm 1.0$ & $<0.001$ \\
25OHD (ng/mL) & $19.1 \pm 6.1$ & $17.1 \pm 5.1$ & $<0.001$ \\
Calcium (mg/dL) & $9.4 \pm 0.4$ & $9.6 \pm 0.3$ & $<0.001$ \\
lonized Calcium (mmol/L) ${ }^{\text {a) }}$ & $1.2 \pm 0.05$ & $1.2 \pm 0.05$ & NS \\
Phosphorus (mg/dL) & $4.8 \pm 0.5$ & $4.9 \pm 0.5$ & 0.014 \\
ALP (IU/L) & $665.8 \pm 190.0$ & $673.7 \pm 181.4$ & NS \\
PTH (pg/mL) & $30.8 \pm 12.5$ & $31.4 \pm 11.4$ & NS \\
\hline Values are presented as numb
\end{tabular}

Values are presented as number (\%) or mean \pm standard deviation. Deficiency, 25OHD, <20 ng/mL; Insufficiency, 25OHD, 20-29.9 $\mathrm{ng} / \mathrm{mL}$; Sufficiency, 25OHD, $\geq 30 \mathrm{ng} / \mathrm{mL}$; BMl, body mass index; 25OHD, 25-hydroxyvitamin D; ALP, alkaline phosphatase; PTH, parathyroid hormone; NS, not significant.

a) Measured in 216 normal weight and 66 overweight children. 

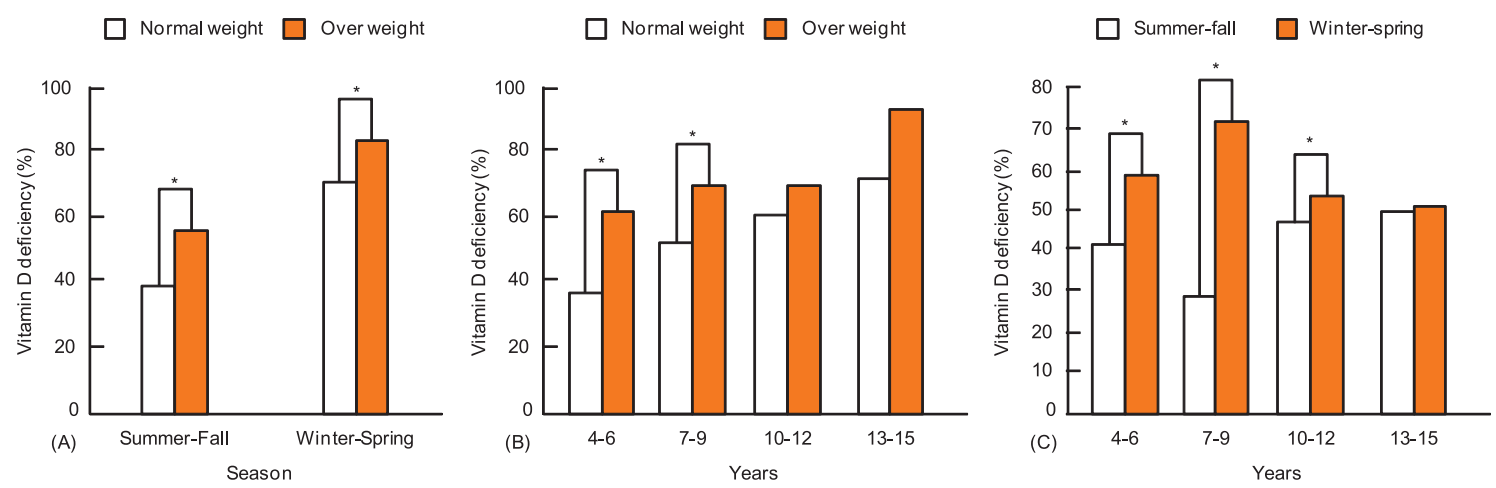

Fig. 1. The prevalence of vitamin D deficiency in normal weight vs. overweight children according to season (A) and age groups (B), and the prevalence of vitamin D deficiency in summer-fall and winter-spring season according to age groups (C). ${ }^{*} P<0.05$.
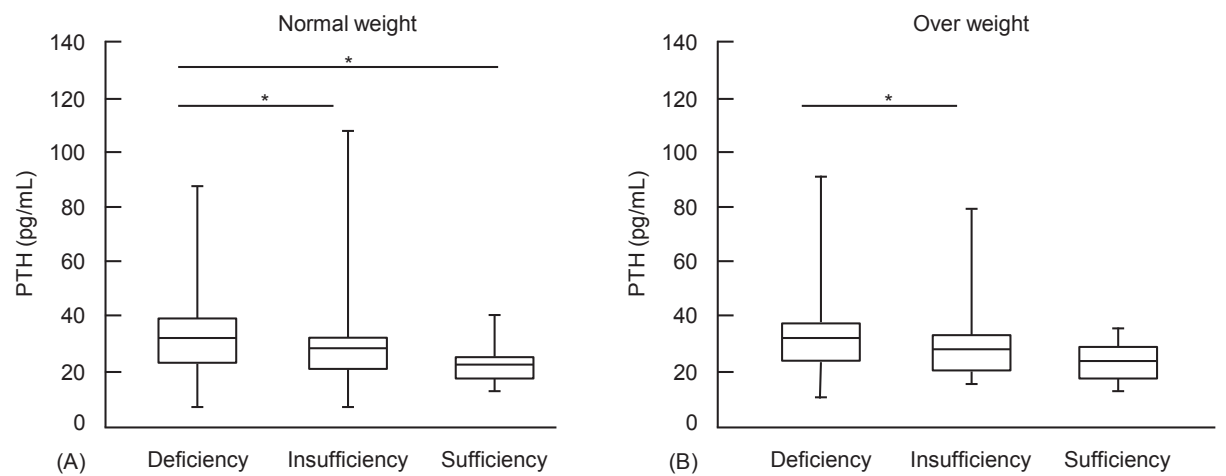

Fig. 2. Mean PTH levels in normal weight (A) and overweight (B) children according to vitamin $D$ status. PTH, parathyroid hormone; Deficiency, 25OHD, $<20 \mathrm{ng} / \mathrm{mL}$; Insufficiency, 25OHD, 20-29.9 ng/mL; Sufficiency, 25OHD, $\geq 30 \mathrm{ng} / \mathrm{mL} .{ }^{*} P<0.05$.

Table 2. The factors associated with vitamin D deficiency in logistic regression analysis

\begin{tabular}{lcr}
\hline Variable & Odds ratio $(95 \% \mathrm{Cl})$ & \multicolumn{1}{c}{$P$-value } \\
\hline Gender & $1.20(0.90-1.60)$ & 0.233 \\
Season (winter-spring) & $4.46(3.45-5.77)$ & $<0.001$ \\
Age group & $1.60(1.36-1.89)$ & $<0.001$ \\
BMI $\geq 85$ th percentile & $2.21(1.62-3.01)$ & $<0.001$ \\
\hline
\end{tabular}

$\mathrm{Cl}$, confidence interval; $\mathrm{BMI}$, body mass index.

The VDD was more common in overweight children compared to normal weight children both in summer-fall $(56.8 \%$ vs. $40.0 \%,=0.001)$ and winter-spring season $(85.0 \%$ vs. $72.3 \%$, $P=0.004)$ (Fig. 1A). When participants were further stratified by age, VDD was more common in overweight children and in winter-spring season in younger age groups, but these differences were not significant in the oldest age group (Fig. 1B, C).

\section{Factors associated with VDD}

Winter-spring season (OR, 4.46; 95\%CI, 3.45-5.77), older age group (OR. 1.60; 95\%CI, 1.36-1.88), and overweight (OR, 2.21; $95 \% \mathrm{CI}, 1.62-3.01)$ were independent determinants of VDD in
Korean children (Table 2).

\section{The relationship of PTH and vitamin D}

Although VDD was very common, PTH level was not elevated in most children. In normal weight group, $13 \mathrm{VDD}$ children (2.4\%) and 7 children (1.7\%) with vitamin D insufficiency showed increased PTH level. Among overweight children, only 1 VDD child (0.6\%) and 1 vitamin D insufficient child (1.5\%) presented high PTH level.

However, the mean PTH level was significantly higher in VDD group compared to vitamin D insufficiency and sufficiency group $(32.6 \pm 12.5 \mathrm{pg} / \mathrm{mL}$ vs. $28.9 \pm 11.7 \mathrm{pg} / \mathrm{mL}$ vs. $23.2 \pm 8.2 \mathrm{pg} / \mathrm{mL}, P<0.001)$. In normal weight group, PTH was significantly higher in VDD group compared to vitamin D insufficiency and sufficiency group $(P<0.001)$. Among overweight children, PTH was also higher in VDD children than in vitamin $\mathrm{D}$ insufficient children $(P<0.001)$. There was no significant difference in PTH levels between normal weight and overweight children in each vitamin D status group (Fig. 2).

The PTH level was inversely related with $25 \mathrm{OHD}$ levels $(r=-0.215, P<0.001)$. The inverse relationship between PTH 
Table 3. The factors associated with PTH in multiple regression analysis

\begin{tabular}{lcccccc}
\hline & \multicolumn{2}{c}{ Normal weight } & & \multicolumn{2}{c}{ Overweight } \\
\cline { 2 - 3 } & \multicolumn{2}{c}{$\beta$} & $P$-value & & $\beta$ & $P$-value \\
\hline 25OHD $(\mathrm{ng} / \mathrm{mL})$ & -0.007 & $<0.001$ & & -0.004 & 0.258 \\
lonized calcium $(\mathrm{mmol} / \mathrm{L})^{\mathrm{a})}$ & -0.594 & 0.007 & & -0.308 & 0.449 \\
BMl z score & 0 & 0.996 & & 0.047 & 0.287 \\
\hline
\end{tabular}

PTH, parathyroid hormone; 25OHD, 25-hydroxyvitamin D; BMI, body mass index.

${ }^{a}$ Measured in 216 normal weight and 66 overweight children.

and 25OHD was significant in both normal weight $(r=-0.210$, $P<0.001)$ and overweight children $(r=-0.235, P<0.001)$. The PTH and ionized calcium level was inversely related $(r=-0.198$, $P=0.004)$ in normal weight children, but was not in overweight children $(r=-0.071, P=0.574)$.

In multiple regression analysis, $25 \mathrm{OHD}(\beta=-0.007, P<0.001)$ and ionized calcium $(\beta=-0.594, P=0.007)$ were independently related with PTH in normal weight group, however, these factors were not significantly related with PTH in overweight group (Table 3).

\section{Discussion}

Our results show that VDD is very common in Korean children and its prevalence increases in winter-spring season, in overweight children and in older age groups. Overweight children are at higher risk for VDD, and the PTH levels were not significantly different between normal weight and overweight children with VDD in the present study.

Vitamin D3 is synthesized in the skin when exposed to ultraviolet light in the range of $290-315 \mathrm{~nm}$ ultraviolet B (UVB). The further apart from the equator, the fewer months of the year contains the UVB sufficient for endogenous skin synthesis ${ }^{9,10)}$ In South Korea (latitude $33-38^{\circ} \mathrm{N}$ ), Vitamin $\mathrm{D}_{3}$ is synthesized in the skin approximately between April and October. Only daylight (between $10 \mathrm{AM}-3 \mathrm{PM}$ ) is effective for vitamin $\mathrm{D}$ synthesis ${ }^{8}$.

In this study, older children were vulnerable to VDD. Most Korean children are engaged in entrance examination for university, and older children have fewer chance of outdoor activity, resulting in high prevalence of VDD throughout the year even in normal weight children ${ }^{6}$.

Obese people tend to have lower vitamin D level than normal weight people ${ }^{11-13)}$. One of the reasons is sedentary life style, as well as due to the lipid solubility of vitamin D, which can be sequestered in adipocytes ${ }^{9}$. However, reports on optimal vitamin D levels in obese children are limited. In the present study, overweight children were at higher risk for VDD. More than half of overweight children had VDD in summer-fall season, and the prevalence of VDD increased to $85 \%$ in winterspring season.

It is not clear yet whether the optimal 25OHD levels are equivalent in normal weight and overweight children or not. It was reported that the relationship between 25OHD and PTH shows a broken-stick appearance, and the inflection point was reported to be around $20 \mathrm{ng} / \mathrm{mL}^{14)}$. In a recent study, the inflection point of 25OHD for PTH elevation was lower in overweight children compared to normal weight children ${ }^{15)}$. However, in the present study, there was no difference in PTH levels between normal weight and overweight children in each vitamin D status group, and we failed to demonstrate the inflection point because the PTH distribution was not suitable for the piecewise regression model (data not shown). Among overweight children, PTH was higher in VDD children than in vitamin $\mathrm{D}$ insufficient children, however, there was no significant difference in PTH levels between vitamin D sufficient group and other vitamin D status groups, probably due to small numbers of vitamin D sufficient children $(n=3)$ in the overweight group.

The PTH and 25OHD showed inverse correlation in both normal and overweight group, in our study, in concordance with recent reports ${ }^{16,17}$. In multiple regression analysis, 25OHD and ionized calcium worked as independent determinants of PTH in normal weight group, but not in overweight group, possibly due to small numbers of overweight children. However, a recent study reported that the inverse relationship between PTH and 25OHD is not observed in obese adults ${ }^{18}$. Further investigation on the vitamin D and PTH metabolism according to adiposity is required to define optimal 25OHD level in overweight children.

It was reported that PTH levels are primarily regulated by ionized calcium and not directly by the level of vitamin $\mathrm{D}^{19)}$. Although the vitamin D levels were lower in overweight children, ionized calcium and PTH levels were comparable in the normal weight and overweight children in the present study. The inverse correlation between PTH and ionized calcium was significant in normal weight group, but this relationship disappeared in overweight group. However, due to small numbers of overweight children in whom ionized calcium was measured, further verification is required to confirm this relationship.

In our data, in spite of high prevalence of VDD, few patients showed elevated PTH level. PTH level was higher in VDD children than in vitamin D insufficient children, but it was within normal range in most children.

The limitation of this study is that this is a hospital based study, and although participants with possible confounding factors such as abnormal laboratory results or specific treatment, it cannot be completely excluded that high risk children are more likely to visit for medical checkup.

Our results suggest that VDD is very common in Korean children, and efforts for improving vitamin D status, such as increasing outdoor activities, are required. Further investigation is warranted to figure out optimal 25OHD level and the relationship with PTH and ionized calcium in overweight children.

\section{Conflict of interest}

No potential conflict of interest relevant to this article was 
reported.

\section{References}

1. Holick MF. Vitamin D deficiency. N Engl J Med 2007;357: 266-81.

2. Chambers ES, Hawrylowicz CM. The impact of vitamin D on regulatory T cells. Curr Allergy Asthma Rep 2011;11:2936.

3. Hypponen E, Laara E, Reunanen A, Jarvelin MR, Virtanen SM. Intake of vitamin $\mathrm{D}$ and risk of type 1 diabetes: a birthcohort study. Lancet 2001;358:1500-3.

4. Muhe L, Lulseged S, Mason KE, Simoes EA. Casecontrol study of the role of nutritional rickets in the risk of developing pneumonia in Ethiopian children. Lancet 1997;349:1801-4.

5. Munns CF, Simm PJ, Rodda CP, Garnett SP, Zacharin MR, Ward LM, et al. Incidence of vitamin D deficiency rickets among Australian children: an Australian Paediatric Surveillance Unit study. Med J Aust 2012;196:466-8.

6. Choi HS, Oh HJ, Choi H, Choi WH, Kim JG, Kim KM, et al. Vitamin D insufficiency in Korea: a greater threat to younger generation: the Korea National Health and Nutrition Examination Survey (KNHANES) 2008. J Clin Endocrinol Metab 2011;96:643-51.

7. Wortsman J, Matsuoka LY, Chen TC, Lu Z, Holick MF. Decreased bioavailability of vitamin D in obesity. Am J Clin Nutr 2000;72:690-3.

8. Holick MF, Binkley NC, Bischoff-Ferrari HA, Gordon CM, Hanley DA, Heaney RP, et al. Evaluation, treatment, and prevention of vitamin D deficiency: an Endocrine Society clinical practice guideline. J Clin Endocrinol Metab 2011;96:1911-30

9. DeLuca HF. Overview of general physiologic features and functions of vitamin D. Am J Clin Nutr 2004;80(6 Suppl):1689S-1696S

10. Holick MF. McCollum Award Lecture, 1994: vitamin
D--new horizons for the 21st century. Am J Clin Nutr 1994;60:619-30.

11. Bell NH, Greene A, Epstein S, Oexmann MJ, Shaw S, Shary J. Evidence for alteration of the vitamin D-endocrine system in blacks. J Clin Invest 1985;76:470-3.

12. Alemzadeh R, Kichler J, Babar G, Calhoun M. Hypovitaminosis D in obese children and adolescents: relationship with adiposity, insulin sensitivity, ethnicity, and season. Metabolism 2008;57:183-91.

13. Snijder MB, van Dam RM, Visser M, Deeg DJ, Dekker JM, Bouter LM, et al. Adiposity in relation to vitamin D status and parathyroid hormone levels: a population-based study in older men and women. J Clin Endocrinol Metab 2005;90:4119-23.

14. Holick MF, Siris ES, Binkley N, Beard MK, Khan A, Katzer JT, et al. Prevalence of Vitamin D inadequacy among postmenopausal North American women receiving osteoporosis therapy. J Clin Endocrinol Metab 2005;90:3215-24.

15. Amini Z, Bryant S, Smith C, Singh R, Kumar S. Is the serum vitamin D-parathyroid hormone relationship influenced by obesity in children? Horm Res Paediatr 2013;80:252-6.

16. Censani M, Stein EM, Shane E, Oberfield SE, McMahon DJ, Lerner S, et al. Vitamin D deficiency is prevalent in morbidly obese adolescents prior to bariatric surgery. ISRN Obes 2013;2013:284516.

17. Deckers MM, de Jongh RT, Lips PT, Penninx BW, Milaneschi Y, Smit JH, et al. Prevalence of vitamin D deficiency and consequences for PTH reference values. Clin Chim Acta 2013;426:41-5.

18. Grethen E, McClintock R, Gupta CE, Jones R, Cacucci BM, Diaz D, et al. Vitamin D and hyperparathyroidism in obesity. J Clin Endocrinol Metab 2011;96:1320-6.

19. Kostyo JL, Goodman HM, editors. Handbook of physiology. Section 7: The endocrine system. Volume V. hormonal control of growth. New York, Oxford University Press, 1999. 
